\title{
Bcl-2 family proteins are essential for platelet survival
}

\author{
H Zhang, ${ }^{1}$ PM Nimmer ${ }^{1}$, SK Tahir ${ }^{1}$, J Chen ${ }^{1}$, RM Fryer ${ }^{3}$, KR Hahn², LA Iciek², SJ Morgan², MC Nasarre ${ }^{2}$, R Nelson ${ }^{3}$, LC Preusser ${ }^{3}$, \\ GA Reinhart ${ }^{3}$, ML Smith ${ }^{1}$, SH Rosenberg ${ }^{1}$, SW Elmore ${ }^{*, 1}$ and C Tse ${ }^{*, 1}$
}

Platelets are relatively short-lived, anucleated cells that are essential for proper hemostasis. The regulation of platelet survival in the circulation remains poorly understood. The process of platelet activation and senescence in vivo is associated with processes similar to those observed during apoptosis in nucleated cells, including loss of mitochondrial membrane potential, caspase activation, phosphatidylserine (PS) externalization, and cell shrinkage. ABT-737, a potent antagonist of Bcl-2, Bcl- $\mathrm{X}_{\mathrm{L}}$, and Bcl-w, induces apoptosis in nucleated cells dependent on these proteins for survival. In vivo, ABT-737 induces a reduction of circulating platelets that is maintained during drug therapy, followed by recovery to normal levels within several days after treatment cessation. Whole body scintography utilizing ${ }^{[111]}$ Indium-labeled platelets in dogs shows that ABT-737-induced platelet clearance is primarily mediated by the liver. In vitro, ABT-737 treatment leads to activation of key apoptotic processes including cytochrome $c$ release, caspase- 3 activation, and PS externalization in isolated platelets. Despite these changes, ABT-737 is ineffective in promoting platelet activation as measured by granule release markers and platelet aggregation. Taken together, these data suggest that ABT-737 induces an apoptosis-like response in platelets that is distinct from platelet activation and results in enhanced clearance in vivo by the reticuloendothelial system.

Cell Death and Differentiation (2007) 14, 943-951. doi:10.1038/sj.cdd.4402081; published online 5 January 2007

Platelets are anucleated blood cells derived from megakaryocytes that are essential for proper hemostasis and thrombosis. $^{1,2}$ Upon blood vessel injury, subendothelial components that become exposed are recognized and serve as a platform for platelet adhesion. Subsequent platelet activation, granule release, and aggregation are essential for the formation of a hemostatic plug that limits blood loss and stimulates repair. ${ }^{2}$ There are several morphological changes associated with platelet activation that are reminiscent of nucleated cell apoptosis. These include phosphatidylserine (PS) externalization, cell shrinkage, and microparticle formation (analogous to membrane blebbing). ${ }^{3}$ Caspase activation may also be involved in platelet activation. ${ }^{4}$ However, this observation remains controversial as caspase inhibitors do not alter a platelet's ability to aggregate. ${ }^{4}$

Apoptosis-like processes have also been linked to platelet biogenesis (i.e., thrombopoiesis) and aging (i.e., senescence). The similarities between platelet biogenesis from megakaryocytes and apoptosis include membrane blebbing, membrane condensation, DNA fragmentation, cell shrinkage, and ultimately the formation of apoptotic bodies. ${ }^{5,6}$ The consequence of this apoptotic process is that each mature megakaryocyte fragments into thousands of platelets. ${ }^{5}$ Once released into the circulation, platelets rapidly age with a halflife of $4-5$ days. ${ }^{7,8}$ As platelets age, they lose their ability to function and are subsequently removed from circulation. The precise mechanism(s) by which platelet senescence is triggered is unclear. However, it has been associated with a decrease in the mitochondrial membrane potential $\left(\Delta \psi_{m}\right)$ and loss of membrane asymmetry, analogous to events observed in apoptosis. 9,10

Apoptosis has been extensively studied in nucleated cells; however, its role in anucleated cells is less defined. Cytochrome $c$, caspase- 9 , caspase-3, and apoptotic protease-activating factor 1 (APAF-1) have been reported to be expressed in platelets indicating that platelets contain the necessary apoptotic machinery to execute programmed cell death. ${ }^{3,11-13}$ Several studies have demonstrated that the $\mathrm{Bcl}-2$ family proteins (i.e., Bax, Bak, $\mathrm{Bcl}-\mathrm{X}_{\mathrm{L}}$, and $\mathrm{Bcl}-2$ ) are also expressed in platelets. ${ }^{11,12,14,15}$ The $\mathrm{Bcl}-2$ family of proteins is the key regulators of mitochondria-dependent apoptosis in nucleated cells and consists of both antiapoptotic $\left(\mathrm{Bcl}-\mathrm{X}_{\mathrm{L}}, \mathrm{Bcl}-2, \mathrm{Bcl}-\mathrm{w}, \mathrm{A} 1, \mathrm{Mcl}-1\right)^{16}$ and proapoptotic (Bak, Bax, Bid, Bim, Bad, Bik, Bmf, Noxa, Puma) ${ }^{17}$ members.

Recently, we reported the discovery of ABT-737, a potent $\left(K_{\mathrm{i}}<1 \mathrm{nM}\right)$ antagonist of a subset of antiapoptotic Bcl-2 family proteins including $\mathrm{Bcl}-2, \mathrm{Bcl}-\mathrm{X}_{\mathrm{L}}$, and $\mathrm{Bcl}-\mathrm{w}$ that induces apoptosis in tumor cells dependent on these proteins for survival. ${ }^{18}$ ABT-737 exhibits single agent killing of both tumor cell lines and primary patient-derived cells, and causes

\footnotetext{
${ }^{1}$ Department of Cancer Research, Global Pharmaceutical Research \& Development, Abbott Laboratories, Abbott Park, IL, USA; ${ }^{2}$ Preclinical Safety Division, Global Pharmaceutical Research \& Development, Abbott Laboratories, Abbott Park, IL, USA and IIntegrative Pharmacology, Global Pharmaceutical Research \& Development, Abbott Laboratories, Abbott Park, IL, USA

${ }^{*}$ Corresponding authors: SW Elmore, Department of Cancer Research, R4N6/AP10-3, Global Pharmaceutical Research \& Development, 100 Abbott Park Road, Abbott Park, IL 60064-6101, USA. Tel: + 1847 937 7850; Fax: + 1847935 1004; E-mail: steve.elmore @ abbott.com and C Tse, Department of Cancer Research, R4N6/AP92, Global Pharmaceutical Research \& Development, 100 Abbott Park Road, Abbott Park, IL 60064-6121, USA. Tel: + 18479352923 ; Fax: + 18479389265 ; E-mail: chris.tse@abbott.com

Keywords: ABT-737; Bcl-2; Bcl- $\mathrm{X}_{\mathrm{L}}$; Bcl-w; apoptosis; platelets; thrombocytopenia

Abbreviations: APAF-1, apoptotic protease-activating factor 1; aPTT, activated Partial Thromboplastin Time; AUC, area under the concentration-time curve; Bcl, B-cell CLL/lymphoma; $C_{\max }$, maximum concentration; DIC, disseminated intravascular coagulation; Mcl, myeloid cell leukemia; PS, phosphatidylserine; PT, Prothrombin Time

Received 23.10.06; revised 13.11.06; accepted 14.11.06; Edited by G Salvesan; published online 5.1.07
} 
complete regression of established tumors in animal models. Although chronic dosing of ABT-737 was well tolerated, we found that $A B T-737$ induced a thrombocytopenia that is maintained throughout the period of drug treatment. This decrease in platelet count was reversible and was not associated with markers of platelet aggregation. Upon further investigation, we demonstrate that ABT-737 induces an apoptotic response in platelets that is distinct from platelet activation and results in platelet clearance from the circulation in vivo. This study suggests that the antiapoptotic Bcl-2 family proteins play a key role in platelet survival.

\section{Results}

ABT-737 induces a rapid, concentration-dependent drop in circulating platelets in vivo. As part of an evaluation of hemodynamic parameters in anesthetized dogs, we observed that escalating intravenous infusions of ABT-737 elicited a concentration-dependent reduction in circulating platelets (Figure 1a). Platelet counts fell by $16 \pm 6,46 \pm 7$, and $100 \%$ of baseline as plasma drug concentrations rose to $7.6,38.4$ and $159.7 \mu \mathrm{M}$, respectively. At the highest dose, platelet counts remained below the limit of detection even as the plasma concentration decreased (to $29.4 \mu \mathrm{M}$ at the $150 \mathrm{~min}$. time point). Infusion of the enantiomer negative control resulted in plasma concentrations similar to those obtained for ABT-737 $(9.4,36.3$ and $130.0 \mu \mathrm{M})$, yet had negligible effects on platelet counts.

ABT-737 had a similar effect on platelets when infused into conscious dogs. A single $15 \mathrm{mg} / \mathrm{kg}$ i.v. dose of ABT-737 (producing a $C_{\max }$ of $18.7 \mu \mathrm{M}$ and area under the concentration-time curve $95 \mu \mathrm{gh} / \mathrm{ml}$ ) induced $\sim 70 \%$ drop in platelet count within $2 \mathrm{~h}$ (Figure 1b). Platelet counts decreased further to $\sim 95 \%$ below baseline at the $6-\mathrm{h}$ time point. A recovery in platelet count was apparent by $24 \mathrm{~h}$, with a return to baseline by $72 \mathrm{~h}$. Compound administration was well tolerated resulting in no adverse clinical signs with the exception of some mild hematomas observed at the site of venipuncture in the

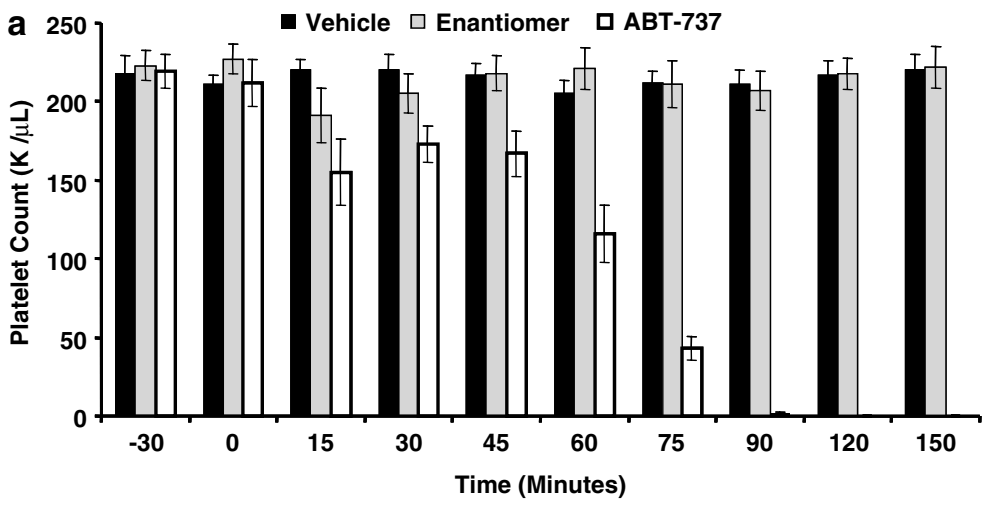

\begin{tabular}{c|cccc} 
Compound & {$[30-\mathbf{m i n}], \mu \mathbf{M}$} & {$[60-\mathbf{m i n}], \mu \mathbf{M}$} & {$[\mathbf{9 0 - m i n}], \mu \mathbf{M}$} & {$[150-\mathbf{m i n}], \mu \mathbf{M}$} \\
\hline ABT-737 & $7.6 \pm 0.8$ & $38.4 \pm 6.3$ & $159.7 \pm 14.2$ & $29.4 \pm 4.2$ \\
Enantiomer & $9.4 \pm 0.8$ & $36.3 \pm 3.0$ & $130.0 \pm 12.6$ & $20.7 \pm 2.6$
\end{tabular}

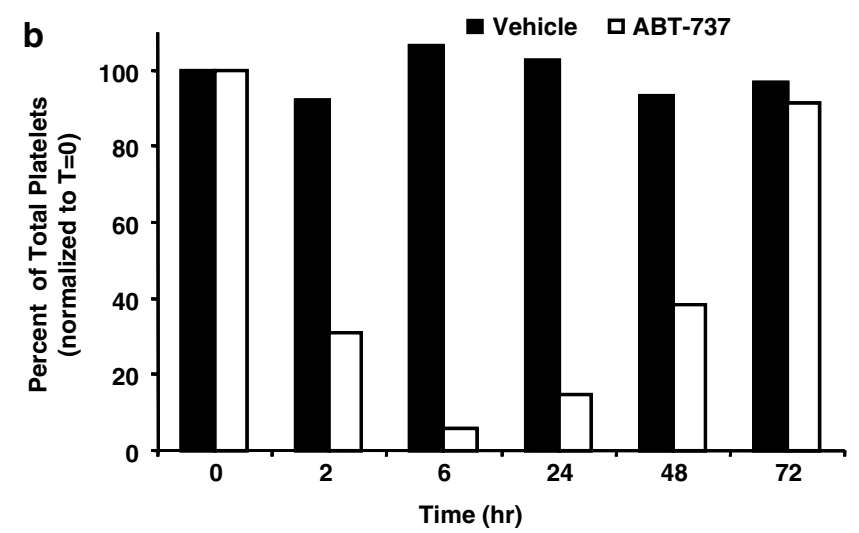

Figure 1 Intravenous administration of ABT-737 in dogs and effects on platelet count. (a) Circulating platelet count (mean \pm S.E.M.) in anesthetized dogs during infusion with increasing concentrations of ABT-737 (open bars), the enantiomer (gray bars), or vehicle (black bars); $n=5-6 /$ group. Statistically significant differences in ABT-737 or the enantiomer versus vehicle were observed at time points $\geqslant 15 \min (P<0.05) . T=30,60$, and 90 min correspond to the end of the first, second, and third infusion, respectively; corresponding plasma concentrations of ABT-737 and the enantiomer are listed in the inset table. (b) Circulating platelet count (mean) in conscious dogs following a single infusion with a $15 \mathrm{mg} / \mathrm{kg}$ dose of ABT-737 (open bars) or vehicle control (black bars); $n=4$ group. The percent of total platelets remaining at each time point is calculated by the following formula: (plate count $T_{T=x}$ /plate count $\left.{ }_{T=0}\right)^{*} 100$ where $x=0,2,6,24,48$, or $72 \mathrm{~h}$ post-infusion 


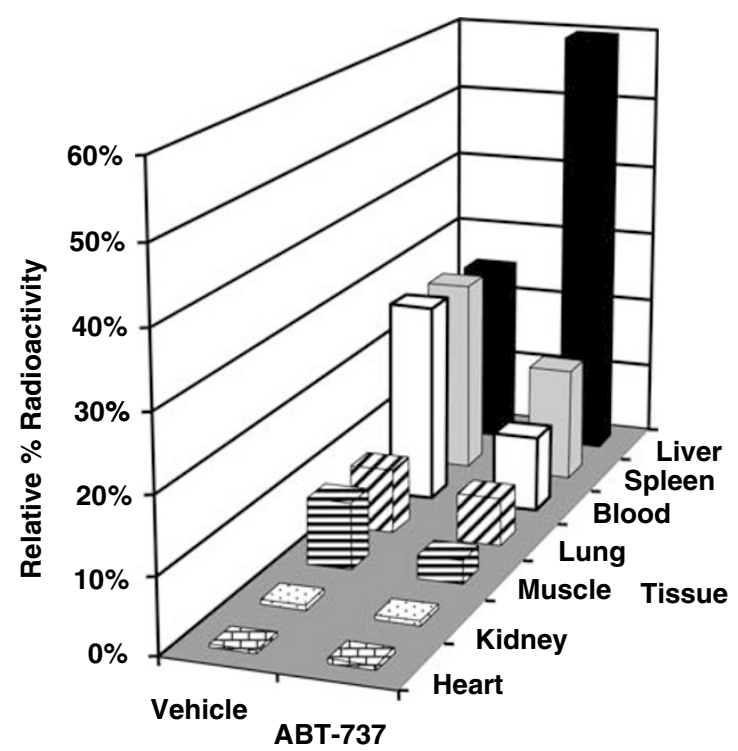

Dose group

Figure 2 ABT-737 induces platelet accumulation in the liver. The relative percent radioactivity within a given tissue is shown. The radioactivity was normalized to the total radioactivity from each animal. Tissues were harvested at the end of the 3-h labeling study; $n=2$-3/group

ABT-737-treated dogs. Furthermore, there was no evidence of disseminated intravascular coagulation (DIC) in these animals as Prothrombin Time (PT), activated Partial Thromboplastin Time (aPTT), and fibrinogen were within normal limits (data not shown).

To determine the fate of platelets upon ABT-737 administration, infusion studies using ${ }^{[111]}$ Indium-oxine-labeled platelets in dogs were performed. Scintigraphic data focusing on the heart, liver, lung, and spleen were collected over the $3 \mathrm{~h}$ study. Vehicle-treated dogs exhibited a steady accumulation of radioactivity in the spleen, a steady state within the heart, and a gradual decrease in the lung and liver (Supplementary Figure S1A), indicating that the labeled platelets partitioned primarily into the spleen. The gradual decrease of radioactivity in the lung and liver is suggestive of circulating platelets in the blood pool. In contrast, dogs infused with $9 \mathrm{mg} / \mathrm{kg}$ of ABT-737 (producing a $C_{\max }$ of $55.8 \mu \mathrm{M})$ exhibited an increase in radioactivity in the liver with reduced uptake in the spleen (Supplementary Figure S1B). Furthermore, no accumulation was observed in the heart and lungs. Assessment of the total radioactivity within several target tissues at the end of the study confirmed these results (Figure 2). A two-fold increase in radioactivity in the liver was observed in ABT-737-treated dogs relative to the vehicle-treated dogs. This is consistent with the histopathologic detection of Kupffer cell hypertrophy and splenic monocyte/macrophage hyperplasia in rats treated with ABT-737 (data not shown). Taken together, this suggests that the rapid clearance of platelets induced by ABT-737 is a consumptive effect mediated through phagocytes of the reticuloendothelial system and not due to DIC or nonspecific sequestration.
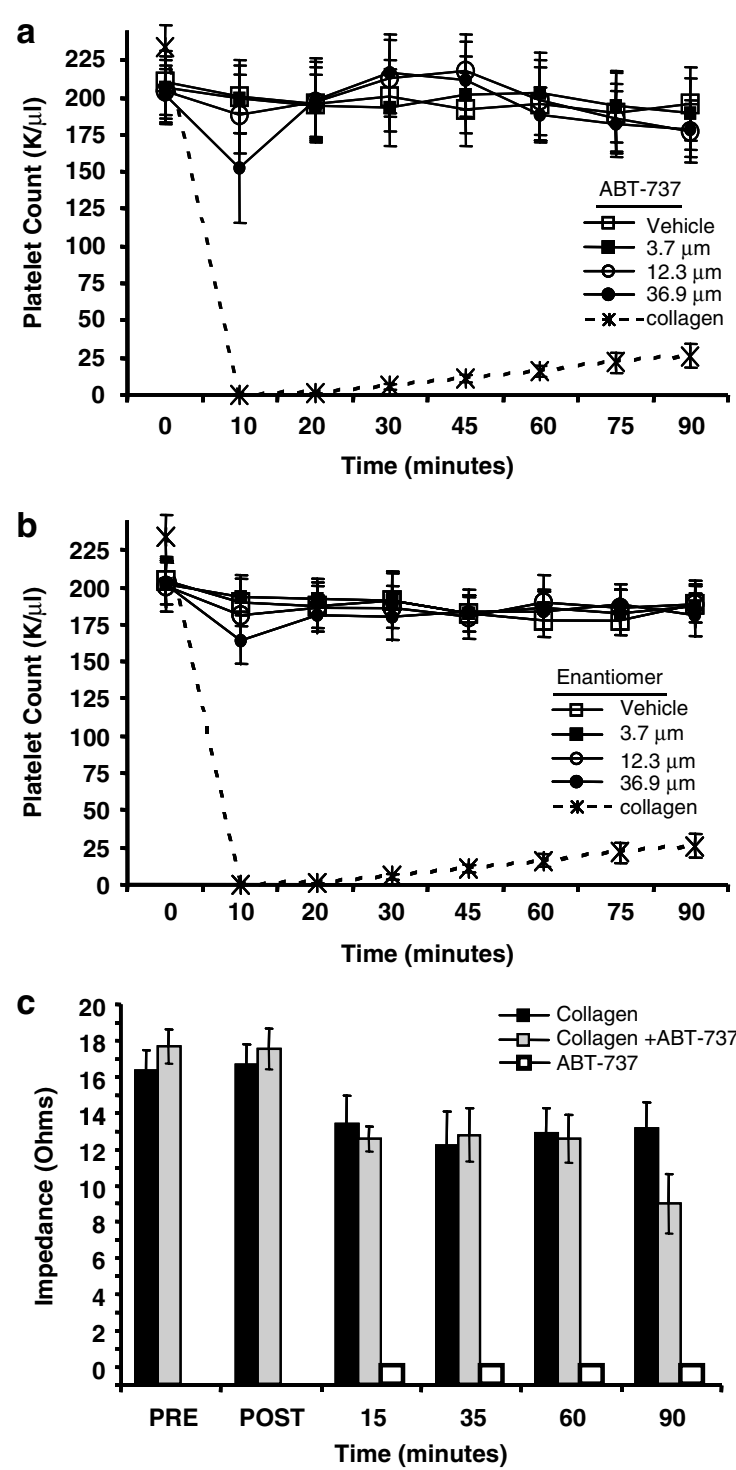

Figure 3 In vitro effects of ABT-737 on whole dog blood platelet count and aggregation potential. (a and $\mathbf{b}$ ) In vitro platelet counts in isolated whole dog blood in the presence of vehicle (- $\square-), 5 \mu \mathrm{g} / \mathrm{ml}$ collagen $\left(-^{*}-\right), 3.7 \mu \mathrm{M}(-\mathbf{\square}-), 12.3 \mu \mathrm{M}(-\bigcirc-)$, or $36.9 \mu \mathrm{M}(--)$ of ABT-737, or the enantiomer over a 90 -min time course. The mean \pm S.E.M. of whole blood isolated from five different dogs is shown. (c) The aggregation response of isolated whole dog blood in response to collagen $(1 \mu \mathrm{g} / \mathrm{ml}$ final concentration) over a 90-min time course. Whole blood was preincubated with

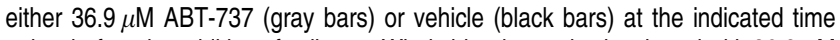
points before the addition of collagen. Whole blood was also incubated with $36.9 \mu \mathrm{M}$ ABT-737 (open bars) alone and evaluated without the addition of collagen. The mean \pm S.E.M. of whole blood isolated from 3-5 different dogs is shown

ABT-737 does not induce platelet aggregation. We next examined the effects of ABT-737 on isolated platelets. Separate aliquots of whole blood from naïve dogs were treated with $3.7,12.3$ or $36.9 \mu \mathrm{M}$ of ABT-737, the enantiomer, or $5 \mu \mathrm{g} / \mathrm{ml}$ collagen, incubated at $37^{\circ} \mathrm{C}$ and platelet counts measured from 0 to $90 \mathrm{~min}$ (Figure $3 a$ and b). Under these conditions, ABT-737 did not significantly affect platelet counts even at concentrations that produced marked reduction of circulating platelets in vivo. The enantiomer control also had no effect. Collagen is a potent platelet 
activator that rapidly induces aggregation, rendering platelets undetectable by the size exclusion techniques used here. ${ }^{19}$ As expected, collagen induced platelet aggregation that manifested as a reduction in measured platelet counts at all time points.

Given the negligible effects of ABT-737 on platelet count in vitro, we next evaluated its effect on platelet aggregation potential. Canine whole blood was treated with either collagen or ABT-737 alone or incubated with $\mathrm{ABT}-737$ for various times and then challenged with collagen. The ability of compounds to induce aggregation was determined by measuring the impedance (Ohms) of the whole blood which is directly proportional to the aggregatory response. ${ }^{20}$ As expected, collagen alone elicited a robust response at all the time points illustrating the stability of the platelets over the course of the study. The ability of the platelets to form aggregates was confirmed both before and after the course of the study by the addition of collagen (Figure 3c; PRE and POST conditions). In contrast, $36.9 \mu \mathrm{M}$ ABT-737 alone did not increase the impedance throughout the entire time course, indicating that it does not directly promote an aggregation response (Figure 3c). However, pretreatment of the whole blood with ABT-737 for $90 \mathrm{~min}$ reduced the collagen-induced aggregation response by approximately $30 \%$. These data indicate that ABT-737 alone does not induce platelet aggregation, but may attenuate the ability of platelets to aggregate in response to stimuli such as collagen.

Platelets undergo apoptosis in response to ABT-737. To determine what factors may govern the response of platelets to ABT-737, Bcl-2 family member (Bcl-2, Bcl- $\mathrm{X}_{\mathrm{L}}, \mathrm{Bcl}-\mathrm{w}$, $\mathrm{Mcl}-1$, Bax, and/or Bak) protein expression levels from five human donors were examined (Figure 4). For comparison,

a

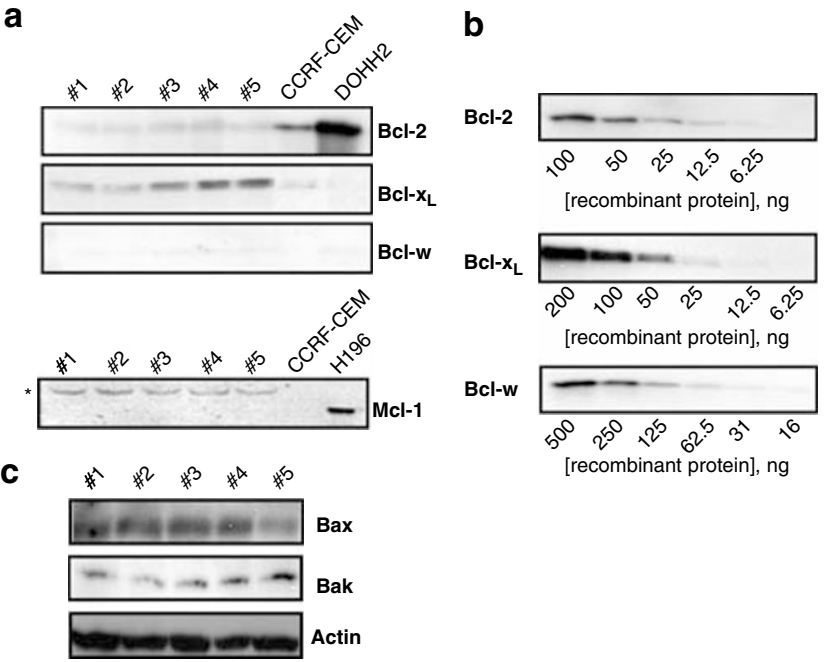

Figure 4 Expression of $\mathrm{Bcl}-2, \mathrm{Bcl}-\mathrm{X}_{\mathrm{L}}, \mathrm{Bcl}-\mathrm{w}, \mathrm{Mcl}-1, \mathrm{Bax}$, and Bak in isolated human platelets. (a) $20 \mu \mathrm{g}$ of protein lysate was isolated from five healthy donors (labeled \#1 to \#5, respectively) and resolved on a 12\% SDS-PAGE, and probed for $\mathrm{Bcl}-2$, Bcl- $\mathrm{X}_{\mathrm{L}}, \mathrm{Bcl}-\mathrm{w}$, and Mcl-1. (*) A nonspecific high molecular weight band is present only in the protein lysates isolated from platelets. (b) Varying amounts of recombinant $\mathrm{Bcl}-2, \mathrm{Bcl}-\mathrm{X}_{\mathrm{L}}$, or $\mathrm{Bcl}-\mathrm{w}$ were resolved on the same gel as a standard to assess relative protein levels. (c) $20 \mu \mathrm{g}$ of protein lysate was resolved on a $12 \%$ SDS-PAGE and probed for Bax and Bak we also evaluated the levels of $\mathrm{Bcl}-2, \mathrm{Bcl}-\mathrm{X}_{\mathrm{L}}, \mathrm{Bcl}-\mathrm{w}$ and $\mathrm{Mcl}-1$ in human tumor cell lines known to be sensitive (CCRF-CEM, DoHH-2) or resistant (H196) to ABT-737. The antiapoptotic proteins $\mathrm{Bcl}-\mathrm{X}_{\mathrm{L}}$ and $\mathrm{Bcl}-2$, as well as the proapoptotic Bax and Bak are all expressed at detectable levels in platelets. Closer examination of the $\mathrm{Bcl}-\mathrm{X}_{\mathrm{L}}$ and $\mathrm{Bcl}-2$ expression levels indicates that $\mathrm{Bcl}-\mathrm{X}_{\mathrm{L}}(25-100 \mathrm{ng} / 20 \mu \mathrm{g}$ total lysate) is the most prevalent followed by Bcl-2 $(6.25-12.5 \mathrm{ng} / 20 \mu \mathrm{g}$ total lysate). In contrast, little to no Bcl-w and $\mathrm{Mcl}-1$ were detected suggesting they are not involved in platelet homeostasis.

We next evaluated the effect of ABT-737 on PS externalization as an initial measure of the ability of ABT-737 to induce apoptosis in human platelets. ABT-737, but not the enantiomer control, induced a rapid and concentration-dependent increase in PS as measured by annexin V staining (Figure 5). This response was evident within $90 \mathrm{~min}$, which is consistent with both the in vivo clearance and ex vivo aggregation studies.

To further characterize the effects of ABT-737 on the apoptotic pathway, additional markers more proximal to the intrinsic (mitochondrial) cell death pathway regulated by the $\mathrm{Bcl}-2$ family were evaluated. Cytochrome $c$ release from the mitochondria was monitored using Western analysis of isolated cytosolic fractions from human platelets (Figure 6a). ABT-737 induced cytochrome $c$ release across a wide range of doses. In contrast, up to $30 \mu \mathrm{M}$ of the enantiomer did not elicit a response. To determine whether platelet activation was also associated with the release of cytochrome $c$, platelets were stimulated with the calcium ionophore, A23187, and examined for cytochrome $c$ release. A23187 $(10 \mu \mathrm{M})$ did not promote cytochrome $c$ release.

ABT-737 induced cytochrome $c$ release was also associated with a dramatic increase in caspase-3 activity as monitored by the specific cleavage of an Ac-DEVD-pNA substrate (Figure $6 \mathrm{~b}$ ). Consistent with the inability to induce cytochrome $c$ release, the enantiomer control did not exhibit a substantial increase in caspase activity during the course of the study. Furthermore, caspase-3-specific cleavage of

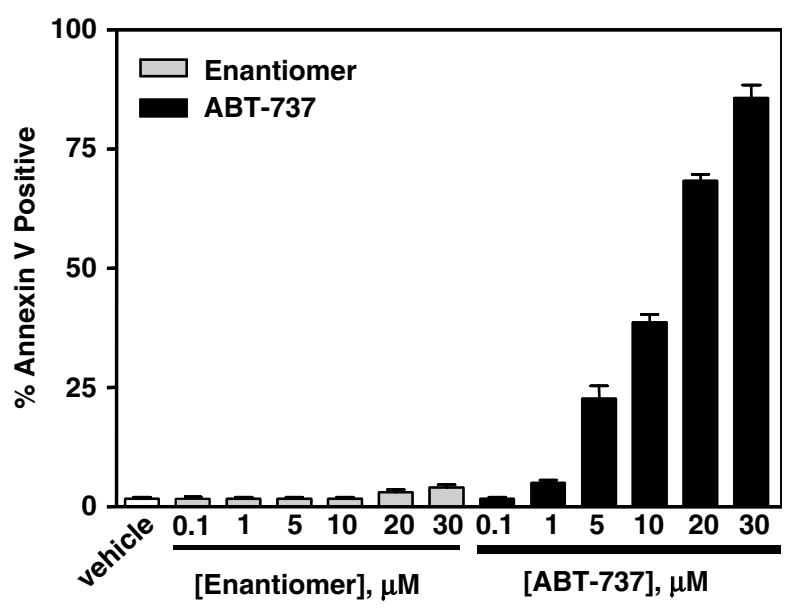

Figure 5 Effect of ABT-737 on human platelet phosphatidylserine (PS) externalization using Annexin V. Percentage of Annexin V-positive (PS positive) platelets following treatment with ABT-737 or the enantiomer at $37^{\circ} \mathrm{C}$ in vitro. The mean \pm S.E.M. from three independent donors is shown 
a

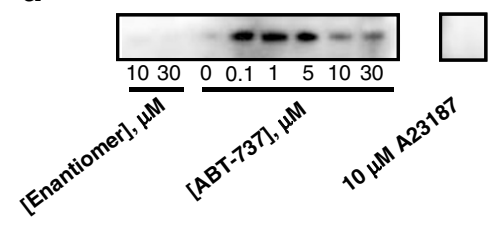

C

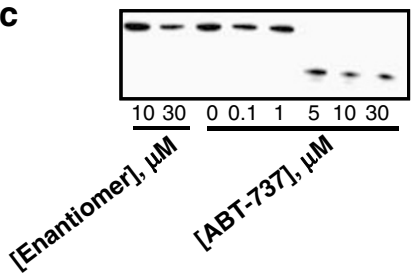

b

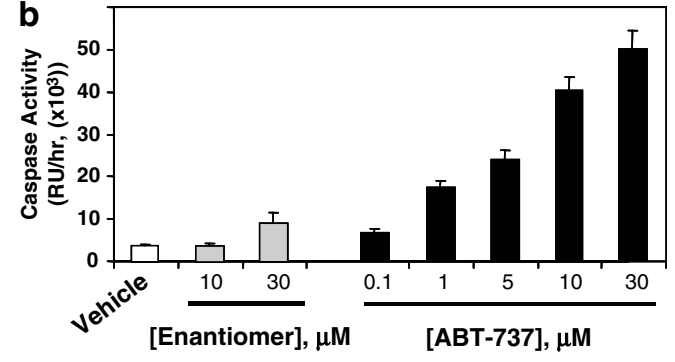

d

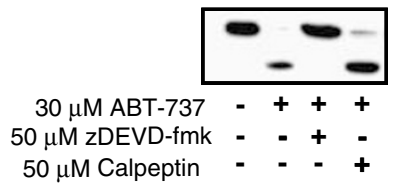

Figure 6 ABT-737 induction of apoptotic signatures. (a) Isolated human platelets were treated with ABT-737, the enantiomer, or A23187 at the indicated concentrations and the cytochrome $c$ release into the cytoplasm was assessed. Platelet cytosol $(10 \mu \mathrm{g}$ ) was resolved on a $12 \%$ SDS-PAGE and probed for cytochrome $c$. (b) Caspase-3 activity in isolated human platelets following treatment with ABT-737 or the enantiomer at the indicated concentrations at $37^{\circ} \mathrm{C}$. The mean \pm S.E.M. from three independent donors is shown. (c) Caspase-3-dependent cleavage of gelsolin following treatment with ABT-737 or the enantiomer. Total lysate (10 $\mu \mathrm{g})$ was resolved on a $12 \%$ SDS-PAGE and probed using an anti-gelsolin antibody. (d) Caspase-3-dependent cleavage of gelsolin following treatment with $30 \mu \mathrm{M} \mathrm{ABT-737}$ in the presence or absence of either zDEVD-fmk or Calpeptin. Total lysate $(10 \mu \mathrm{g})$ was resolved on a $12 \%$ SDS-PAGE and probed using an anti-gelsolin antibody

gelsolin into 39 and $41 \mathrm{kDa}$ fragments was also observed with ABT-737 but not its enantiomer (Figure 6c). Gelsolin is an actin-regulatory protein that has been shown to be a substrate of caspase-3..$^{3,12}$ The cleavage of gelsolin was inhibited by the caspase-3 inhibitor zDEVD-fmk but not the calpain inhibitor calpeptin, indicating that the observed gelsolin cleavage is mediated by caspase-3 and not calpain (Figure 6d). Taken together, these data indicate that ABT-737 activates the classical markers of apoptosis in platelets. The fact that the less active enantiomer has no effect in these assays suggests these changes are the direct result of inhibition of the antiapoptotic Bcl-2 family members.

ABT-737 has modest effects on granule release. Upon platelet activation, a series of granules are released that are essential for the full activation response. ${ }^{21}$ To further investigate other direct effects of $A B T-737$ on platelet dynamics, isolated platelets were treated with ABT-737 and classical markers of granule release were monitored.

The lysosomal granule marker, CD63, is not affected by $A B T-737$. CD63 is a specific marker of the lysosomal granule that becomes externalized on the surface of the platelets as a result of platelet activation. ${ }^{21}$ The effects of ABT-737 on lysosomal granule release were assessed by flow cytometry studies using an antibody against CD63. As a reference, the ability of a known platelet activator, A23187, was also evaluated in all the granule release assays. As shown in Figure 7a, a slight dose-response was apparent in platelets upon treatment with ABT-737 but not its enantiomer. However, less than $15 \%$ of platelets exhibited CD63-positive staining when exposed to $30 \mu \mathrm{M}$ ABT-737 compared to $65 \%$ of platelets induced to express CD63 by treatment with $20 \mu \mathrm{M}$ of the calcium ionophore, A23187. These data suggest that ABT-737 alone has modest effects on lysosomal granule release.
The alpha granule/activation marker, $P$-selectin, is not affected by $A B T-737$. P-selectin is a protein normally stored in the alpha granules that becomes exposed on the surface of platelets upon platelet activation. ${ }^{21}$ To assess the effects of ABT-737 on alpha granule release, the surface expression of $\mathrm{P}$-selectin was evaluated using an anti-CD62 $p$ antibody. There is a modest increase in P-selectin expression in the presence of ABT-737 but not its enantiomer (Figure 7b). However, a much greater increase in P-selectin expression is observed in the presence of $20 \mu \mathrm{M}$ A23187 ( 75\%) compared to $30 \mu \mathrm{M} \mathrm{ABT-737} \mathrm{(} \mathrm{13 \% ).}$

$A B T-737$ does not activate GPIIb/IIla. GPIIb/IIla is a platelet surface protein that undergoes a conformational change upon platelet activation and mediates interactions between the platelets and other coagulation factors such as fibrinogen. ${ }^{22}$ The active conformation of GPIIb/IIla is readily detectable by PAC-1, an antibody that specifically recognizes only the active conformation of GPIIb/IIla. As shown in Figure 7c, both ABT-737 and its enantiomer were unable to activate GPIlb/IIla in isolated human platelets at all concentrations tested. In contrast, $20 \mu \mathrm{M}$ A23817 induced PAC-1 staining in $\sim 40 \%$ of the platelets. These data indicate that $\mathrm{ABT}-737$ does not promote $\alpha$-granule release or GPIIb/ IIla activation.

$A B T-737$ induces dense granule release. Dense granules contain several molecules including ADP and serotonin, which are released upon platelet activation. To determine if ABT-737 induces dense granule release, isolated human

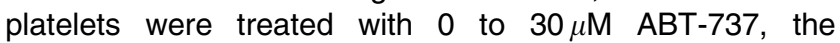
enantiomer, $20 \mu \mathrm{M}$ A23187, or vehicle control at $37^{\circ} \mathrm{C}$ and the serotonin released into the medium was measured by ELISA. ABT-737, but not its enantiomer, induced a dosedependent increase in serotonin levels (Figure 8). The maximum response observed was similar to that induced by the platelet activator A-23187. 

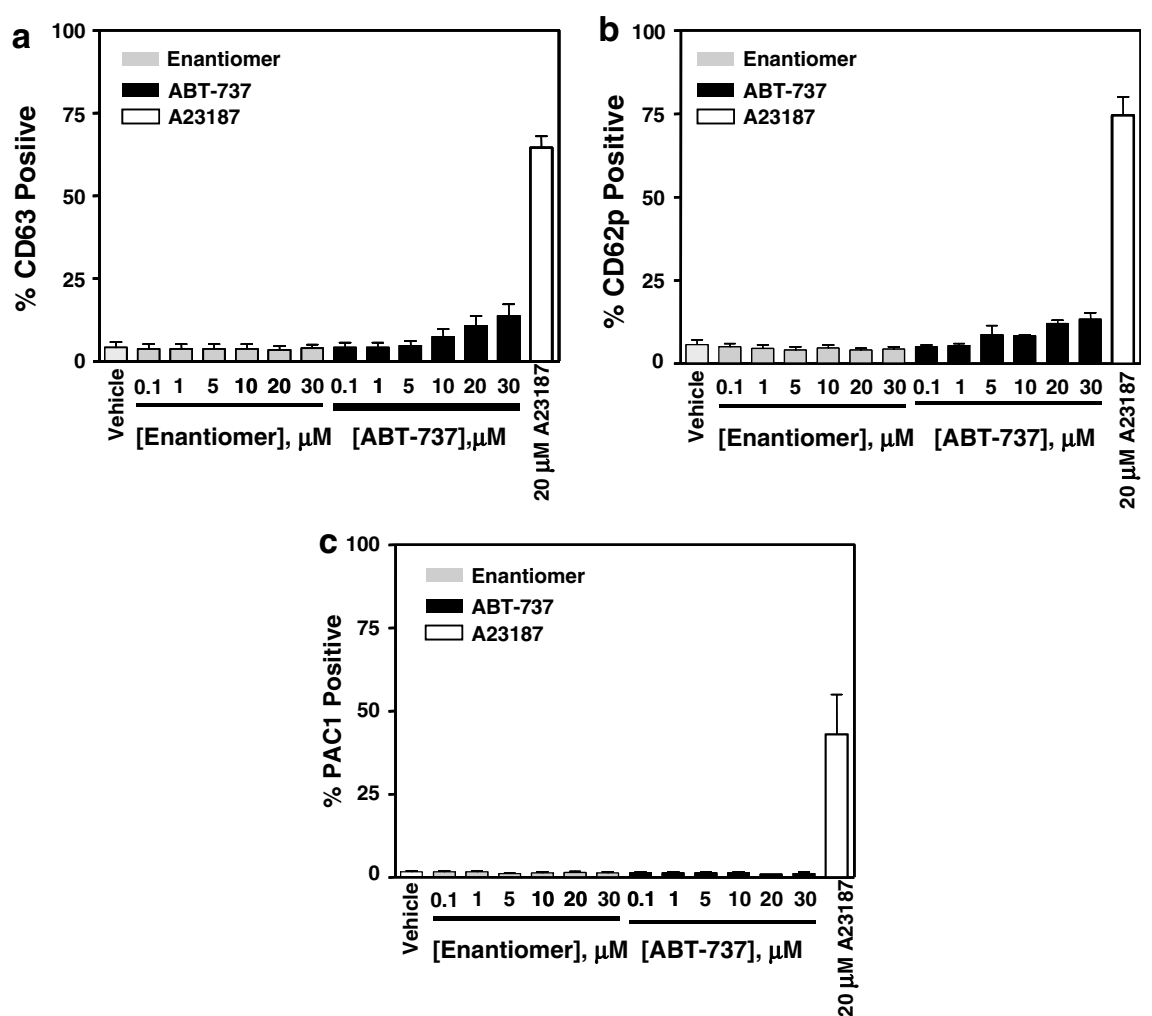

Figure 7 Flow cytometric analyses of the effects of ABT-263 on human platelet granule release in vitro. Measurement of surface markers of lysosomal granule (CD63) and alpha granule release (CD62p) as well as activation of platelet-membrane GPIll/llla complex (PAC-1; an indicator of platelet activation) following treatment with ABT-737, the enantiomer, or A23187 (calcium ionophore) at $37^{\circ} \mathrm{C}$ in vitro. (a) Percent of CD63-positive staining platelets. (b) Percent of P-selectin (CD62p)-positive staining platelets. (c) Percent of PAC-1-positive staining platelets. The mean \pm S.E.M. from three independent donors is shown

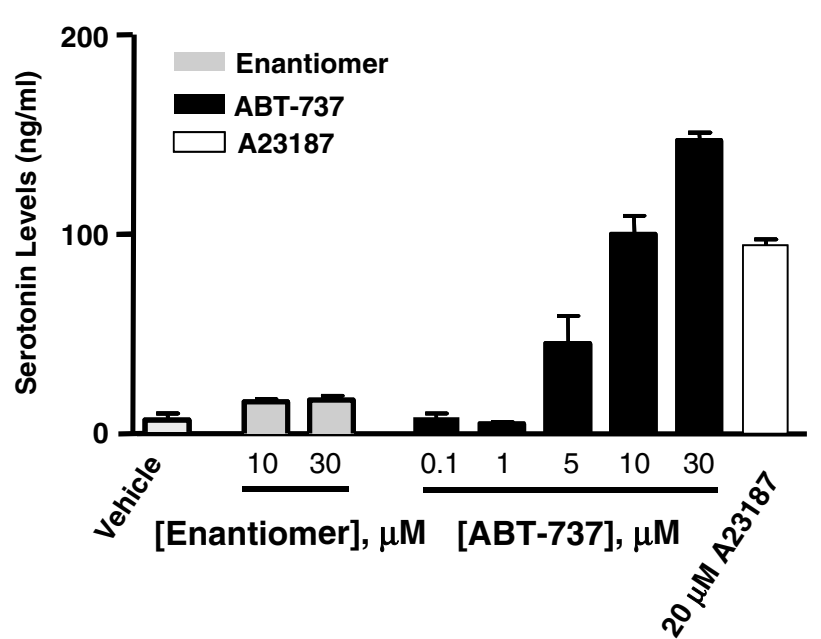

Figure 8 Effects of ABT-737 on dense granule release. Amount of serotonin released after incubation at $37^{\circ} \mathrm{C}$. Serotonin release measured using an ELISA kit as described in the Methods section. The mean \pm S.E.M. from three independent donors is shown

\section{Discussion}

The mechanism(s) of apoptosis and the role of the Bcl-2 family proteins have been extensively investigated in nucleated cells; however, less is known about apoptosis and the role of the Bcl-2 family proteins in anucleated cells. Although chromosomal condensation and DNA fragmentation are hallmarks of apoptosis, the nucleus itself is not an absolute requirement. Previous studies have shown that apoptotic agents promote morphological changes in anucleated cytoplast that resemble characteristics of programmed cell death. ${ }^{23,24}$ In platelets, the morphological changes of apoptosis closely resemble those of activation, including PS externalization, microparticle release (i.e., apoptotic bodies), and cell shrinkage. Platelet aging is also characterized by PS externalization; however, it is unclear whether this is reflective of an apoptotic process or an incomplete platelet activation event. Taken together, the distinguishing factors and the role of apoptosis in platelets is unclear.

ABT-737 is a small molecule antagonist of the prosurvival $\mathrm{Bcl}-2$ family proteins $\mathrm{Bcl}-\mathrm{X}_{\mathrm{L}}, \mathrm{Bcl}-2$, and $\mathrm{Bcl}-\mathrm{w}$ that induces apoptosis in tumor cells in a mitochondria-dependent fashion. ${ }^{18}$ Treatment of ABT-737 in dogs leads to a rapid, dosedependent decrease in circulating platelets that return to baseline within 72-h post dosing. This time course is inconsistent with thrombocytopenia induced by traditional cytotoxic chemotherapy and suggests a mechanism resulting in consumption of circulating platelets rather than that of decreased production by the megakaryocytes (Figure 1). Pathologic evaluation of these animals identified no evidence of consumptive coagulopathy as a result of platelet activation and clotting. Indium-labeling studies indicated the liver and to 
a lesser extent, the spleen are the primary tissues of accumulation suggesting that phagocytosis of affected platelets by the reticuloendothelial system may be the primary mechanism of clearance (Figure 2).

The process of apoptosis can be viewed as a cascade of events initiating from the accumulation of a death signal(s), release of apoptotic factors from the mitochondria, activation of initiator/effector caspases, ultimately leading to cell death. ${ }^{16}$ Our studies demonstrate that ABT-737 initiates the apoptotic cascade in isolated platelets. First, we observe the release of cytochrome $c$ (Figure $6 \mathrm{a}$ ). Consistent with previous reports, the platelet activator, A23187, did not induce cytochrome $c$ release indicating this is specific to apoptosis. ${ }^{3,11}$ Second, the release of cytochrome $c$ corresponded with caspase-3 activation and subsequent cleavage of gelsolin. Consistent with previous reports, we also observe that gelsolin cleavage is inhibited by the presence of caspase 3-like inhibitor, zDEVD-fmk but not calpeptin indicating that the proteolytic cleavage is driven by caspase- 3 not calpain..$^{3,4}$ Third, we observe a rapid, dose-dependent increase in PS externalization (Figure 5). Interestingly, the rapid induction of $P S$ externalization in platelets ex vivo parallels the rapid clearance of platelets in vivo, suggesting that PS externalization may be the primary signal for the removal of affected platelets. In support of this hypothesis, previous studies have linked platelet clearance with the loss of membrane asymmetry (i.e., PS externalization). ${ }^{9,10}$ PS externalization on cells has also been shown to signal the specific engulfment of these unwanted cells by phagocytes leading to clearance from the circulation . ${ }^{9,15,25}$ Finally, the fact that the enantiomer negative control does not activate the apoptotic cascade at equivalent concentrations supports the notion that $\mathrm{ABT}-737$ is promoting platelet apoptosis through the direct inhibition of the $\mathrm{Bcl}-2$ family proteins.

Based on the relative protein levels of the $\mathrm{Bcl}-2$ family members in isolated human platelets, $\mathrm{Bcl}-2$ may play a minor role in platelet survival. The lower expression levels of $\mathrm{Bcl}-2$ are consistent with previous observations indicating the presence of negligible amounts of $\mathrm{Bcl}-2$ in mature platelets. ${ }^{26}$ In comparison, the levels of $\mathrm{Bcl}-\mathrm{X}_{\mathrm{L}}$ in platelets are significantly greater than $\mathrm{Bcl}-2$, suggesting that $\mathrm{Bcl}-\mathrm{X}_{\mathrm{L}}$ may play a larger role in platelet survival. Studies examining apoptotic markers in stored platelets indicates that $\mathrm{Bcl}-\mathrm{X}_{\mathrm{L}}$ levels rapidly decrease as platelets age and lose viability in vitro, further supporting a role for $\mathrm{Bcl}-\mathrm{X}_{\mathrm{L}}$ in platelet survival. ${ }^{12}$ We were unable to detect $\mathrm{Bcl}-\mathrm{w}$ or $\mathrm{Mcl}-1$, indicating they are not involved in platelet survival. Taken together, these data suggest that the effects of ABT-737 on platelets are primarily due to the inhibition of $\mathrm{Bcl}-\mathrm{X}_{\mathrm{L}}$; however, this hypothesis has to be further investigated.

In contrast to apoptosis, full platelet activation requires the concerted actions of several processes including the release of a series of granules (i.e., alpha, lysosomal, and dense) as well as the conformational activation of surface proteins. ${ }^{21}$ The successful release of these granules is necessary for the aggregation and clotting function of platelets. Our studies demonstrate that ABT-737 induces an apoptotic response in platelets that is distinct from that of platelet activation. First, concentrations up to $30 \mu \mathrm{M}$ ABT-737 did not significantly alter platelet count, in vitro, indicating that platelets were not aggregating in response to ABT-737 treatment (Figure 3a). The inability of ABT-737 alone to induce platelet aggregation was also confirmed by impedance aggregometry studies (Figure 3c). Second, ABT-737 only induces a modest release of the alpha and lysosomal granules, which was far less robust than the platelet activator, A23187 (Figure 7). Third, ABT-737 does not induce the conformational activation of GPIIb/IIla, which is essential for coagulation. The pivotal role of GPIIb/IIla in platelet activation is reflected by the fact that several GPIIb/ IIla antagonists are currently being evaluated as anti-platelet agents. ${ }^{27-29}$ ABT-737 does promote dense granule release to levels similar to that of A23187 (Figure 8). However, the relevance of this in vitro effect is unclear given that ABT-737 does not cause platelet aggregation. Furthermore, no increase in circulating serotonin levels was observed in vivo after administration of an equipotent analog in dogs suggesting that platelets were cleared from circulation before the potential release of serotonin (data not shown).

In summary, we propose that ABT-737 induces apoptosis in platelets causing rapid PS externalization, which leads to the clearance of affected platelets from circulation. The rapid kinetics of ABT-737-induced thrombocytopenia in vivo along with the robust and rapid rebound of platelet counts post dosing suggests an effect on mature platelets and not on megakaryocytes and platelet production. The fact that the enantiomer control had no effect on platelets strongly suggests this phenomenon to be mediated by inhibition of the antiapoptotic $\mathrm{Bcl}-2$ family proteins such as $\mathrm{Bcl}-\mathrm{X}_{\mathrm{L}}$. These studies have not only provided mechanistic insight into a unique drug-induced thrombocytopenia but also have identified the potential role of antiapoptotic Bcl-2 family proteins as critical survival factors for mature platelets.

\section{Materials and Methods}

Dog ABT-737 infusion studies - anesthetized dog. The effects of ABT-737, its enantiomer, and vehicle (PEG-400) on platelet count were assessed in the anesthetized dog. Briefly, male beagle dogs $(n=5-6 /$ group; $8-12 \mathrm{~kg}$ ) were anesthetized with pentobarbital $(35.0 \mathrm{mg} / \mathrm{kg}$, i.v.) and immediately placed on a constant intravenous infusion $(6.0 \mathrm{mg} / \mathrm{kg} / \mathrm{h})$ to maintain a surgical plane of anesthesia. Animals were intubated and ventilated with room air; expiratory $\mathrm{CO}_{2}$ was monitored with an end-tidal $\mathrm{CO}_{2}$ monitor (Criticare Systems; Model POET TE; Waukesha, WI, USA) and maintained at $4-5 \%$. Polyethylene catheters were inserted into the right femoral vein and artery for infusion of ABT-737, the enantiomer or vehicle and collection of blood samples, respectively. Subsequently, animals were instrumented to record numerous cardiovascular parameters as previously described..$^{30,31}$ Following completion of the surgical protocol, animals were allowed to recover for $1 \mathrm{~h}$. Stable baseline values were collected for 30-min before a series of three 30-min i.v. infusions of ABT-737 or the enantiomer $(0.05$, 0.16 , and $0.5 \mathrm{mg} / \mathrm{kg} / \mathrm{min}$ ) or vehicle; animals were monitored for 1 -h post-treatment. Arterial blood was collected via the femoral artery at 15-min intervals beginning at time zero. Platelet count was determined from whole blood samples (Cell-Dyn 3700, Abbott Laboratories), and plasma was separated by centrifugation and frozen at $-80^{\circ} \mathrm{C}$ before analytical determination of drug concentrations. At each time point, change in platelet count from baseline was determined by repeated measures ANOVA, Dunnet's post-test, and statistical significance set at $P<0.05$.

Dog ABT-737 infusion studies - conscious dog. The affects of ABT737 were also evaluated in the conscious dog. Dogs received single dosages of 0,5 , or $15 \mathrm{mg} / \mathrm{kg}$ via an intravenous catheter (jugular vein) with Captisol as the vehicle over a 4-h infusion period. Two dogs per sex were utilized for the vehicle control and ABT-737-treated groups. Hematology and clinical chemistry evaluations were performed on the day following dosing for each of the two dosing periods $(0 / 5$ and $0 / 15 \mathrm{mg} / \mathrm{kg}$ ). Additional samples were taken at 1,2 , and 3 weeks post dosing of the 
$15 \mathrm{mg} / \mathrm{kg}$ dose. Detailed clinical observations, body weights, and food consumption were evaluated throughout the study.

After an approximately 3-week recovery period, the dogs from the doseescalation study received a single dose of $15 \mathrm{mg} / \mathrm{kg}$, with samples for hematology taken at 2, 6, 24, 48, 72, and $96 \mathrm{~h}$ post dosing. Platelet count was determined from whole blood samples on the Cell-Dyn 3700 .

\section{[111] Indium-oxine-labeled platelet studies - anesthetized} dog. Battelle Toxicology (Columbus, OH, USA) carried out radiolabeled platelet studies according to institutional protocol. Briefly, indium-111 solution was incubated with oxine sulfate and then incubated with autologous platelets. Before infusion with labeled platelets and compound, dogs were anesthetized with sodium pentobarbital and anesthesia maintained by continuous infusion for the duration of the study. ${ }^{[111]}$ Indium-oxine-labeled platelets were infused over a 10-min period followed by a 5 -min recovery and then a 30 -min infusion of either the vehicle control or ABT-737 (9 mg/kg; producing a $C_{\max }$ of $55.8 \mu \mathrm{M}$ and AUC $\left.\sim 2204 \mu \mathrm{g} \mathrm{h} / \mathrm{ml}\right)$. Scintigraphs were collected once per minute during the infusion periods and then every 15-min fore $3 \mathrm{~h}$. Animals were killed and tissues harvested during necropsy for assessment of radioactivity.

In vitro platelet count and aggregation studies. Blood was obtained from the jugular vein of fasted dogs and mixed in a 9:1 (vol : vol) ratio with sodium citrate (3.8\%). The blood was then diluted 1:1 (vol: vol) with Hanks Balanced Salt Solution (HBSS). An aliquot of this blood/HBSS mixture was sent for platelet count measurement on a Cell-Dyn 3700 that utilizes a size-based gating system to count platelets. Briefly, platelets were placed on a rocker at $37^{\circ} \mathrm{C}$. An aliquot of blood was removed at the following time points $T=0,10,20,30,45,60,75$, and $90 \mathrm{~min}$ for platelet counting.

For aggregation studies, two separate test tubes of prepared whole dog blood were placed on a rocker at room temperature for mixing, one for treating with $A B T$ 737 and one to use as the POST control sample. ABT-737 was added to a final concentration of $36.88 \mu \mathrm{M}$ and before the addition of collagen. A Chronolog Aggregometer was used to determine the aggregatory response to collagen, a well-characterized platelet agonist. Briefly, $1 \mathrm{ml}$ of blood (mixture) was placed in a cuvette, warmed to $37^{\circ} \mathrm{C}$, and then collagen was added to a final concentration of $1 \mu \mathrm{g} / \mathrm{ml}$ at the indicated time points. Each blood sample was tested at the following time points: $T=0,15,35,60$, and $90 \mathrm{~min}$. To account for any effects of time on platelet's aggregation response, the $T=0$ sample (before drug treatment) was compared to a separate (untreated) POST sample in each time course experiment. The maximum Ohms resistance over 10-min post collagen challenge was used to determine the aggregatory response.

Preparation of platelet-rich plasma (PRP). Human PRP (i.e., platelets) was isolated from whole blood from healthy donors on the day of each study. Whole blood was obtained using a protocol approved by the Western Internal Review Board from healthy 2-week medication-free individuals who have given written consent. For canine whole blood, blood was isolated from naïve animals. In total, $90 \mathrm{ml}$ of whole blood was extracted into $9 \mathrm{ml}$ of $\mathrm{Na}$ Citrate $(3.8 \%$ solution) for platelets. Whole blood specimens were then transferred into $15 \mathrm{ml}$ centrifuge tubes and centrifuged at 1000 r.p.m. for $10 \mathrm{~min}$ in a clinical centrifuge. The plasma (top layer) above the buffy coat was pooled and set aside. For Platelet Poor Plasma (PPP), the residual blood was centrifuged at 3000 r.p.m. for $10-\mathrm{min}$ and the plasma pooled.

SDS-PAGE and protein immunoblotting. PRP was isolated from five different donors and whole-cell lysates were made using the CelLytic-M mammalian cell lysis/extraction reagent (Sigma). Protein lysate $(20 \mu \mathrm{g})$ was resolved by gel electrophoresis on a $15 \%$ SDS-PAGE. Western analyses were performed using the following conditions: Bcl-2 (mouse mAb; Santa Cruz, 1:500); Bcl-xL (mouse mAb; BD Pharmigen, 1:500), Bcl-w (mouse pAb from Cell Signaling, 1:500); Mcl-1 (rabbit mAb; Epitomics, 1:500); cytochrome $c$ (rabbit pAb; Clontech, 1:50); and gelsolin (mouse mAb; BD Pharmigen 1:2500). Signal was resolved by ECL (Amersham).

Cytochrome $c$ release and gelsolin cleavage. Isolated platelets were treated with compounds at $37^{\circ} \mathrm{C}$ for $5 \mathrm{~h}$, lysed in digitonin buffer (10 $\mathrm{mM}$ Hepes, $\mathrm{pH} 7.5,70 \mathrm{mM}$ Sucrose, $210 \mathrm{mM}$ mannital, $1 \mathrm{mM}$ EDTA, $100 \mathrm{mM} \mathrm{KCl}, 0.025 \%$ digitonin, and protease inhibitors), and $8 \mu \mathrm{g}$ of cytosol was used for Western analysis. To evaluate gelsolin cleavage, isolated platelets were lysed in Ripa buffer
(Sigma), and $8 \mu \mathrm{g}$ of whole-cell lysate was used for Western analysis. To study the effect of caspase/calpain inhibitors, the PRP was preincubated with $50 \mathrm{uM} \mathrm{z-DEVD-}$ fmk (Sigma) or 50 uM Calpeptin (Sigma) for 20 min at RT.

Caspase-3 activation assay. PRP was incubated with the compounds at various concentrations for $5 \mathrm{~h}$ at $37^{\circ} \mathrm{C}$. After incubation, the caspase activity was measured using the Caspase-Glo 3/7-assay kit (Promega) according to the manufacturer's specifications. The luminescence generated from the samples was quantitated using an LJL Analyst plate reader. Data analysis was performed in Microsoft Excel.

Phosphatidylserine externalization assay. PRP was diluted to $1 \times 10^{7}$ cells $/ \mathrm{ml}$ with Platelet Poor Plasma (PPP) from the same donor. Diluted platelets were incubated with $\mathrm{ABT}-737$, the enantiomer or a known platelet activator, A23187, at various concentrations for $90 \mathrm{~min}$ at $37^{\circ} \mathrm{C}$. After incubation, Annexin V binding buffer (BD Biosciences, Palo Alto, CA, USA) was mixed with treated platelets and Annexin V-APC (BD Biosciences) at a 9:1:2 ratio. Samples were gently mixed by rocking and incubated at room temperature for an additional $20 \mathrm{~min}$. Samples were further diluted five-fold with binding buffer and read on a FACSCalibur (BD Biosciences).

Serotonin release assay. PRP was incubated with $A B T-737$, the enantiomer, or $\mathrm{A} 23187(20 \mu \mathrm{M})$ at various concentrations for $5 \mathrm{~h}$ at $37^{\circ} \mathrm{C}$. After incubation, platelets were centrifuged at $13000 \times g$ for $10 \mathrm{~min}$. Plasma was harvested and the serotonin levels were assayed using an ELISA kit from Labor Diagnostika Nord GmbH \& Co. KG (Germany) according to the manufacturer's suggestion.

Flow cytometry analysis of CD markers. PRP was diluted to $1 \times 10^{7}$ cells/ml with PPP from the same donor. Diluted platelets were incubated with ABT737, the enantiomer, $\mathrm{A} 23187$, or thrombin at various concentrations for 90 -min at $37^{\circ} \mathrm{C}$. Cells were stained with the following antibodies conjugated to the indicated fluorochrome: CD62p-APC + CD63-PE or PAC1-FITC and incubated for $20 \mathrm{~min}$ at room temperature in the dark. Cells were fixed with the addition of Uti-lyse Reagent A (DakoCytomation, Carpinteria, CA, USA). Samples were then diluted with phosphate-buffered saline (without $\mathrm{Ca}^{2+} / \mathrm{Mg}^{2+}$ ) and counted within $3 \mathrm{~h}$ after fixing

Acknowledgements. We thank Drs. Kennan C Marsh, and Joy L Bauch, and Edith J McDonald for the pharmacokinetic analyses and isolation of whole dog blood.

\section{Duality of interest}

All the authors are employees of Abbott Laboratories whose potential product was studied in the present work.

1. Troy GC. An overview of hemostasis. Vet Clin North Am Small Anim Pract 1988; 18 (1): 5-20.

2. Packham MA. Role of platelets in thrombosis and hemostasis. Can J Physiol Pharmacol 1994; 72 (3): 278-284

3. Wolf BB, Goldstein JC, Stennicke HR, Beere H, Amarante-Mendes GP, Salvesen GS et al. Calpain functions in a caspase-independent manner to promote apoptosis-like events during platelet activation. Blood 1999; 94 (5): 1683-1692.

4. Shcherbina A, Remold-O'Donnell E. Role of caspase in a subset of human platelet activation responses. Blood 1999; 93 (12): 4222-4231.

5. Kaluzhny Y, Ravid K. Role of apoptotic processes in platelet biogenesis. Acta Haematol 2004; 111 (1-2): 67-77.

6. Patel SR, Hartwig JH, Italiano Jr JE. The biogenesis of platelets from megakaryocyte proplatelets. J Clin Invest 2005; 115 (12): 3348-3354.

7. Stuart MJ, Murphy S, Oski FA. A simple nonradioisotope technic for the determination of platelet life-span. N Engl J Med 1975; 292 (25): 1310-1313.

8. Tsan MF. Kinetics and distribution of platelets in man. Am J Hematol 1984; 17 (1): 97-104.

9. Pereira J, Palomo I, Ocqueteau M, Soto M, Aranda E, Mezzano D. Platelet aging in vivo is associated with loss of membrane phospholipid asymmetry. Thromb Haemost 1999; 82 (4): 1318-1321.

10. Pereira J, Soto M, Palomo I, Ocqueteau M, Coetzee LM, Astudillo $S$ et al. Platelet aging in vivo is associated with activation of apoptotic pathways: studies in a model of suppressed thrombopoiesis in dogs. Thromb Haemost 2002; 87 (5): 905-909.

11. Li J, Xia Y, Bertino AM, Coburn JP, Kuter DJ. The mechanism of apoptosis in human platelets during storage. Transfusion 2000; 40 (11): 1320-1329.

12. Bertino AM, Qi XQ, Li J, Xia Y, Kuter DJ. Apoptotic markers are increased in platelets stored at 37 degrees C. Transfusion 2003; 43 (7): 857-866. 
13. Clarke MCH, Savill J, Jones DB, Noble BS, Brown SB. Compartmentalized megakaryocyte death generates functional platelets committed to caspase-independent death. $J$ Cell Biol 2003; 160 (4): 577-587.

14. Vanags DM, Orrenius S, Aguilar-Santelises M. Alterations in Bcl-2/Bax protein levels in platelets form part of an ionomycin-induced process that resembles apoptosis. Br J Haematol 1997; 99 (4): 824-831.

15. Brown SB, Clarke MC, Magowan L, Sanderson H, Savill J. Constitutive death of platelets leading to scavenger receptor-mediated phagocytosis. A caspase-independent cell clearance program. J Biol Chem 2000; 275 (8): 5987-5996.

16. Coultas L, Strasser A. The role of the Bcl-2 protein family in cancer. Semin Cancer Biol 2003; 13 (2): 115-123.

17. Gelinas C, White E. BH3-only proteins in control: specificity regulates MCL-1 and BAK-mediated apoptosis. Genes Dev 2005; 19 (11): 1263-1268.

18. Oltersdorf T, Elmore SW, Shoemaker AR, Armstrong RC, Augeri DJ, Belli BA et al. An inhibitor of Bcl-2 family proteins induces regression of solid tumours. Nature 2005; 435 (7042): 677-681.

19. Kahn ML. Platelet-collagen responses: molecular basis and therapeutic promise. Semin Thromb Hemost 2004; 30 (4): 419-425.

20. Manoharan A, Gemmell R, Brighton T, Dunkley S, Lopez K, Kyle P. Thrombosis and bleeding in myeloproliferative disorders: identification of at-risk patients with whole blood platelet aggregation studies. Br J Haematol 1999; 105 (3): 618-625.

21. Rendu F, Brohard-Bohn B. The platelet release reaction: granules' constituents, secretion and functions. Platelets 2001; 12 (5): 261-273.

22. Kawabata K, Nakai S, Miwa M, Sugiura T, Otsuka Y, Shinzato T et al. Platelet GPIlb/llla is activated and platelet-leukocyte coaggregates formed in vivo during hemodialysis. Nephron 2002; 90 (4): 391-400.

23. Jacobson MD, Burne JF, Raff MC. Programmed cell death and Bcl-2 protection in the absence of a nucleus. EMBO J 1994; 13 (8): 1899-1910.
24. Martin SJ, Finucane DM, Amarante-Mendes GP, O'Brien GA, Green DR Phosphatidylserine externalization during CD95-induced apoptosis of cells and cytoplasts requires ICE/CED-3 protease activity. J Biol Chem 1996; 271 (46): 28753-28756.

25. Fadok VA, Bratton DL, Rose DM, Pearson A, Ezekewitz RA, Henson PM. A receptor for phosphatidylserine-specific clearance of apoptotic cells. Nature 2000; 405 (6782): 85-90.

26. Sanz C, Benet I, Richard C, Badia B, Andreu EJ, Prosper F et al. Antiapoptotic protein Bcl$\mathrm{x}(\mathrm{L})$ is up-regulated during megakaryocytic differentiation of $\mathrm{CD} 34(+)$ progenitors but is absent from senescent megakaryocytes. Exp Hematol 2001; 29 (6): 728-735.

27. Proimos G. Platelet aggregation inhibition with glycoprotein Ilb-Illa inhibitors. J Thromb Thrombolysis 2001; 11 (2): 99-110.

28. Judge HM, Buckland RJ, Holgate CE, Storey RF. Glycoprotein Ilb/llla and P2Y12 receptor antagonists yield additive inhibition of platelet aggregation, granule secretion, soluble CD40L release and procoagulant responses. Platelets 2005; 16 (7): 398-407.

29. Lecompte T, Hardy J-F. Antiplatelet agents and perioperative bleeding: [Les inhibiteurs plaquettaires et le saignement perioperatoire]. Can J Anesth 2006; 53 (6_suppl): S103-S112.

30. Fryer RM, Preusser LC, Calzadilla SV, Hu Y, Xu H, Marsh KC et al. (-)-9S)-9-(3-bromo-4fluorophenyl)-2, 3, 5, 6, 7, 9-hexahydrothieno[3,2-b]quin olin-8(4H)-one 1,1-dioxide (A278637), a novel ATP-sensitive potassium channel opener: hemodynamic comparison to ZD-6169, WAY-133537, and nifedipine in the anesthetized canine. J Cardiovasc Pharmacol 2004; 44 (2): 137-147.

31. Fryer RM, Rakestraw PA, Preusser LC, Brune ME, Carroll WA, Buckner SA et al. Pharmacological characterization of the novel dihydropyridine potassium channel opener, (9R)-9-(3-iodo-4-methylphenyl)-5, 9-dihydro-3H-furo[3,4-b]pyrano[4,3-e]pyri dine-1, 8(4H, $7 H)$-dione (A-325100), and the regulation of cardiovascular function in conscious and anesthetized beagle dogs. J Cardiovasc Pharmacol 2005; 46 (2): 232-240.

Supplementary Information accompanies the paper on Cell Death and Differentiation website (http://www.nature.com/cdd) 